\title{
Approach to parathyroid carcinoma (PC): seven cases and a review of the literature
}

\author{
Yuanyuan Zheng', Junping Wen², Wei Lin², Lixiang Lin², Gang Chen² \\ ${ }^{1}$ Department of VIP Clinic, ${ }^{2}$ Department of Endocrinology, Fujian Provincial Hospital, Fujian Medical University, Fuzhou, China \\ Contributions: (I) Conception and design: Y Zheng; (II) Administrative support: J Wen; (III) Provision of study materials or patients: W Lin; (IV) \\ Collection and assembly of data: Y Zheng; (V) Data analysis and interpretation: L Lin, G Chen; (VI) Manuscript writing: All authors; (VII) Final \\ approval of manuscript: All authors. \\ Correspondence to: Gang Chen. Department of Endocrinology, Fujian Provincial Hospital, Fujian Medical University, Fuzhou, China. \\ Email: chengangfj@163.com.
}

\begin{abstract}
To summarize the experience in the diagnosis and treatment of seven cases with parathyroid carcinoma (PC). We collect seven parathyroid carcinoma cases of Fujian Provincial Hospital from January 2009 to December 2018. Reviewing and concluding the seven collected cases referring to relative reference domestic and abroad. All of the seven cases have hypercalcemia and a high level of parathyroid hormone (PTH) that were over two folds of the normal upper limit, even over 36 folds. The PC in seven cases were confirmed by routine histopathology and immunohistochemistry. All the cases went through surgery. Parathyroid carcinoma shows no specificity in clinical feature, it usually implicates in skeleton and urinary system. Routine serum calcium examination, serum PTH determination are helpful diagnosing PC before operation. The appropriate surgical procedure is parathyroidectomy combined with ipsilateral total thyroidectomy and neck dissection in levels of II, III, IV, V and VI.
\end{abstract}

Keywords: Parathyroid carcinoma (PC); clinical feature; pathological examination

Submitted Nov 03, 2019. Accepted for publication Mar 10, 2020.

doi: $10.21037 /$ tcr-19-2368

View this article at: http://dx.doi.org/10.21037/tcr-19-2368

\section{Introduction}

Parathyroid carcinoma (PC) is an uncommon malignancy originated from parathyroid parenchymal cells. Less than 2,000 recorded cases reported in literature since Armstrong firstly reported PC with hypercalcemia $(1,2)$. There is no clear diagnostic standard for PC, and it poses a diagnostic challenge because of the absence of characteristics that allow definite distinction of malignant from benign disease. It is generally believed that if a patient's serum calcium level is over $3.5 \mathrm{mmol} / \mathrm{L}$, and the parathyroid hormone $(\mathrm{PTH})$ is over 2 to 5 folds of the normal upper limit, or the neck mass may be touched, or with the symptom of vocal cord paralysis, bones, kidneys and other related manifestations, the diagnosis of PC should be highly taken into consideration (3). Surgery is the only effective therapy to control hypercalcemia and decrease tumor loads, both at initial resection and at the time of recurrence of metastasis (4). The aim of this study is to appraise the recent literature on management of PC with respect to seven illustrative cases of PC treated consecutively at our hospital over the last nine years.

\section{Methods}

We present seven cases of PC treated in Fujian Provincial Hospital, and a literature review and propose the approach to PC.

\section{Case}

Case 1: a 35-year-old male, admitted with pain in both lower limbs, weakness and vomiting. On examination, a $2 \mathrm{~cm} \times 2 \mathrm{~cm}$ mass was found in the upper pole of the right thyroid gland, with a hard texture, unclear boundary 
and without tenderness. It could move up and down with swallowing, and no vascular murmur was heard. Doppler ultrasound suggested right neck substantial occupation with multiple calcification, from parathyroid gland? Parathyroid imaging showed focal concentration in the upper right lobe of the thyroid gland, with possible parathyroid hyperplasia. His serum calcium level was $4.9 \mathrm{mmol} / \mathrm{L}$ (normal range 2.1-2.7 mmol/L), PTH was over $2,834 \mathrm{pg} / \mathrm{mL}$ (normal range $15-88 \mathrm{pg} / \mathrm{mL}$ ). "Right parathyroid gland resection and right residual thyroidectomy" was scheduled on August 17, 2009. Pathology confirmed PC with necrosis, tumor invasion of the envelope, invasion of blood vessels and tumor plug was seen in the blood vessels. Immunohistochemistry revealed Synaptophysin (Sy) (-), S100 (-), Neuron specific enolase (NSE) (-), Ki67 $(25 \%+)$, Chromogranin A (CgA) $(++)$, Calcitonin (CT) (-), Thyroglobulin $(\mathrm{Tg})(+)$. The serum calcium was $1.4 \mathrm{mmol} / \mathrm{L}$ and PTH was $65 \mathrm{pg} / \mathrm{mL}$. The patient died of severe pneumonia after surgery in one month.

Case 2: a 44-year-old man with a background history of chronic renal failure came to our hospital for dizziness. Clinical examination was normal. Doppler ultrasound scan showed left parathyroid adenomatous enlargement with calcification. Serum calcium was $4.2 \mathrm{mmol} / \mathrm{L}$, and PTH was $3,243.8 \mathrm{pg} / \mathrm{mL}$. He underwent surgery of "Left upper parathyroid gland and left thyroidectomy" on April 08, 2010. Intraoperative frozen section examination suggested parathyroid tumor. Pathology revealed parathyroid adenocarcinoma, tumor thrombus was found in the blood vessels, invading the capsule and surrounding thyroid tissues. Immunohistochemistry: thyroid transcription factor-1 (TTF-1) (-), Tg (-), Sy (-), CgA (-), Ki67 (10\%+), P53 (+), CD34 (-). Postoperative serum calcium was $1.8 \mathrm{mmol} / \mathrm{L}$ and PTH was $43.1 \mathrm{pg} / \mathrm{mL}$. The 5 -year followup did not show residual-recurrent disease.

Case 3: a 72-year-old man was admitted with the chief complaint of hoarseness for one month. A hard mass about $2 \mathrm{~cm} \times 1.5 \mathrm{~cm}$ could be touched in the right thyroid lobe, with clear boundary and uneven surface. It could move up and down with swallowing without tenderness. Several dural lymph nodes of about $0.5 \mathrm{~cm} \times 0.5 \mathrm{~cm}$ were palpable in the neck, with poorly defined boundaries and no obvious tenderness. Doppler ultrasound scan showed a solid mass in the right lobe of the thyroid gland. Thyroid Stimulating Hormone (TSH), free triiodothyronine (FT3), free thyroxine (FT4) were normal, and serum calcium was $2.5 \mathrm{mmol} / \mathrm{L}$, PTH was not detected. "Right thyroid lobe and isthmus resection and right neck lymph node dissection" was performed on
May 20, 2010. Pathology confirmed PC, interstitial fibrous hyperplasia with sarcomatoid hyperplasia, invasion of the thyroid capsule and surrounding fibrous tissue, no capsule invasion of blood vessels. No cancer metastasis was found in the lymph nodes. Immunohistochemistry showed Ki67 (20\%), P53 (+), Galetin3 (+), CT (-), Tg (-), CgA (-), NSE $(+)$, Sy (-). Serum calcium was $1.9 \mathrm{mmol} / \mathrm{L}$ and PTH was $28.3 \mathrm{pg} / \mathrm{mL}$ after surgery. The 5 -year follow-up did not show residual-recurrent disease.

Case 4: a 57-year-old man was admitted with the chief complaint of repeated sacrococcygeal pain for two years. Clinical examination was otherwise normal. Doppler ultrasound revealed isoecho in the lower right lobe of the thyroid gland. Serum calcium was $2.61 \mathrm{mmol} / \mathrm{L}$ and PTH $900.10 \mathrm{pg} / \mathrm{mL}$. The surgery of "right parathyroid gland exploration and right parathyroid lesion resection and right thyroid and isthmus resection and central area lymph node dissection" was done on February 06, 2017. Pathology revealed PC with invasion of the tumor envelope and the surrounding thyroid tissue, and tumor thrombus was seen in the blood vessels. Immunohistochemistry showed Ki67 $(5 \%+)$, P53 (-), CK19 (positive parathyroid tumor, negative thyroid gland), mesothelial cell (MC) (positive of few parathyroid tumor cells and thyroid cells), CD34 (+). Serum calcium was $2.25 \mathrm{mmol} / \mathrm{L}$ and PTH was $32.01 \mathrm{pg} / \mathrm{mL}$. The 5 -year follow-up did not show residual-recurrent disease.

Case 5: a 39-year-old man with a background history of maintenance hemodialysis was admitted with raised serum calcium $(2.75 \mathrm{mmol} / \mathrm{L})$, elevated PTH $(1,718 \mathrm{pg} / \mathrm{mL})$ come to our hospital. Clinical examination was normal. Ultrasound showed the enlargement of bilateral parathyroid, and secondary hyperparathyroidism with adenoma formation was considered. Parathyroid imaging showed abnormal nodular concentration in the lower posterior lobe of the thyroid, considered to be triad hyperparathyroidism. The patient underwent "parathyroid gland subtotal excision" on March 06, 2010. Pathology revealed parathyroid adenomatous hyperplasia, active cell growth, some areas invaded the capsule and showed infiltrating growth. Tumor cells were found in the interfibrous vessels, considering some areas of cancer (PC). Immunohistochemistry revealed P53 (individual cells were positive), Ki67 (5\%+), TTF-1 (-). The 5-year follow-up did not show residual-recurrent disease.

Case 6: a 43-year-old man was admitted with bilateral knee pain for six months. Clinical examination was normal. The patient's serum calcium was $3.01 \mathrm{mmol} / \mathrm{L}$, parathyroid hormone was $800.5 \mathrm{pg} / \mathrm{mL}$. Doppler ultrasound found 
hypoecho in the dorsal thyroid of parathyroid, parathyroid adenomatoid changes were considered. The left dorsal thyroid was slightly hyperechoic, and the nature of the parathyroid gland was to be determined, considering the possibility of parathyroid gland. "Right parathyroid gland lesion resection and left parathyroid gland exploration and partial left parathyroid gland autotransplantation" was performed on December 09, 2010. Pathology confirmed PC with invasion of capsule and vascular. Immunohistochemistry showed CT (-), CgA (+), Tg (-), Carcinoembryonic antigen (CEA) (-), Ki67 (20\%+), Sy (+). Serum calcium was $1.98 \mathrm{mmol} / \mathrm{L}$ and PTH was $6.73 \mathrm{pg} / \mathrm{mL}$ after the surgery. The 5 -year follow-up did not show residual-recurrent disease.

Case 7: a 63-year-old female underwent a surgery of "left thyroid and isthmus resection, right inferior parathyroid carcinoma dilated resection (right inferior thyroid resection, right central region lymph node dissection), left parathyroid biopsy" four years ago, and the pathology confirmed PC. Her PTH fluctuated at $86.9-119 \mathrm{pg} / \mathrm{mL}$, and serum calcium fluctuated at $2.37-2.67 \mathrm{mmol} / \mathrm{L}$. And she was admitted with large neck mass for three months. A mass about $1 \mathrm{~cm} \times 0.5 \mathrm{~cm}$ in size could be touched on the right thyroid gland, with unclear boundary, moving up and down with the thyroid gland, and no tenderness, no vascular murmur was heard. The calcium was $3.33 \mathrm{mmol} / \mathrm{L}$, and the PTH was $161.5 \mathrm{pg} / \mathrm{mL}$. Parathyroid imaging showed a posterior medial nodular image of the lower right lobe of the thyroid gland, which was taken $99 \mathrm{mTc}-\mathrm{MIBI}$ with high function and slow excretion. It was considered that parathyroid tumor recurred. She underwent the surgery of "right neck mass resection and right residual thyroidectomy", and the pathology confirmed PC, with invasion of peripheral adipose tissue, involving the surrounding thyroid, but no lymph nodes involvement. Immunohistochemistry revealed Ki67 (5\%+), CK (pan) (+), TTF-1 (-), Tg (-), PTH (+++), CD 56(+), CgA (++), Sy (++), paired box homeodomain proteins 8 (PAX8) (-), BcL-2 (+++). The serum calcium was $2.13 \mathrm{mmol} / \mathrm{L}$ and PTH was $124.5 \mathrm{pg} / \mathrm{mL}$.

\section{Results}

Among the seven cases, there were six males and one female, aged 35-63 years, with an average age of 50.5 years. The duration of illness is six months to five years. Three of whom had bone pain, one had hoarseness. Physical examination revealed anterior cervical nodules in three patients. The laboratory examination showed the seven cases serum calcium of $2.61-4.9 \mathrm{mmol} / \mathrm{L}$, with an average of
$3.46 \mathrm{mmol} / \mathrm{L}$ (the normal range is $2.1-2.7 \mathrm{mmol} / \mathrm{L}$ ), among which two cases had serum calcium over $3.75 \mathrm{mmol} / \mathrm{L}$. PTH range from 476.4 to $3,243.8 \mathrm{pg} / \mathrm{mL}$, with an average of $1,662.1 \mathrm{pg} / \mathrm{mL}$. All patients underwent surgical treatment, and pathology confirmed PC.

\section{Discussion}

\section{Epidemiology}

$\mathrm{PC}$ is an extremely rare tumor, with an estimated prevalence of $0.005 \%$ of all cancers (5). It accounts for a very small proportion in primary hyperparathyroidism (PHPT), less than $1 \%$ in foreign literature, and about $5.96-7.1 \%$ reported in Chinese literature (6). There was no significant gender difference in the incidence of $\mathrm{PC}$. The diagnosis age of PC patients reported in foreign literatures is usually earlier than that of benign parathyroid lesions, most of which are 45-59 years old (5), while there was no significant difference in age between benign and malignant parathyroid diseases reported in China $(7,8)$.

\section{Etiology and pathogenesis}

Pathogenesis of PC is still unknown. It may be sporadic or occur in the context of a genetic endocrine syndrome as in hyperparathyroidism/jaw tumour syndrome (HPT-JT), multiple endocrine neoplasia type 1 (MEN1), type 2A (MEN2A), and familial isolated hyperparathyroidism (FIHP) (9). Most scholars believe there is no evidence of $\mathrm{PC}$ arising from transformation of parathyroid adenoma (PA). This may be due to different genetic changes between PA and PC (6).

\section{Diagnosis}

\section{Clinical feature}

The clinical manifestations of PC are usually more severe than PA patients. $90.0 \%$ of patients with PC had nonspecific clinical symptoms, which were mainly caused by excessive PTH secretion by parathyroid tumor cells, and manifested as hyperparathyroidism and hypercalcemia (10). PC patients often exhibit symptoms and complications of hypercalcemia, bone and renal disease, abdominal pain, nausea, pancreatitis and peptic ulcer (6). If hypercalcemic crisis occurs, patients will appear coma, mental disorders and other neuropsychiatric symptoms, such as Arrhythmia, hypertension and other cardiovascular symptoms (11). However, about $10.0 \%$ of patients with PC lack typical 
clinical manifestations and have poor prognosis (10).

\section{Laboratory tests}

Serum calcium levels in PC have been noted to be frequently higher than $3.5 \mathrm{mmol} / \mathrm{L}$ ( $v s .<2.8 \mathrm{mmol} / \mathrm{L}$ in benign disease), while PTH levels have commonly been 3 to 10 times as high as the upper normal limit, even 20 times. In this study, the highest PTH level in patients was 36 times higher than the upper normal limit. However, patients with benign parathyroid disease may have a milder increase in PTH, typically about twice as much (12). Xue et al. found that serum calcium, PTH and maximum tumor diameter were risk factors for PC, especially PTH value was $560 \mathrm{pg} / \mathrm{mL}$, the sensitivity and specificity were $84.2 \%$ and $73.6 \%$ respectively (13).

\section{Imaging}

Imaging is useful for tumor localization to some extent, it mainly includes ultrasound, MIBI imaging, CT, MRI or PET-CT. In this study, three patients had palpable masses in the neck, which is rare in benign parathyroid tumor. Ultrasound or CT imaging of large parathyroid tumors with calcification may be suggestive, but cannot reliably discriminate benign from malignant disease. Therefore, when the serum calcium level is over $3 \mathrm{mmol} / \mathrm{L}$ and the parathyroid lesion is over $3 \mathrm{~cm}$ (so-called $>3+>3$ rule) or the ionic calcium exceeds $1.77 \mathrm{mmol} / \mathrm{L}$, the possibility of PC should be fully alert (14). In addition, primary hyperparathyroidism may be a component of multiple endocrine adenomatosis, adrenal ultrasound is necessary to detect the presence of a neoplasm of the adrenal gland (pheochromocytoma) before emergency surgery for hypercalcemia according to the consensus of Chinese experts (6).

\section{Cytology, histopathology}

As early as 1973, Schantz et al. (15) first reported morphologic principles defining PC: lobulated and hard, with dense white fibers closely adhering to the surrounding tissues, cell nests arranged in clusters and beams, abnormal cells, and invasion of enveloped vessels. It is worth mentioning that some parathyroid adenomas show the histological characteristics of malignant tumors, which are characterized by funicular fibers, marked trabecular growth, increased mitosis (once per 10 high power regions), tumor necrosis and incomplete invasion of normal parathyroid tissue. As mitosis increases, we should be highly alert to the possibility of canceration (16). At present, fine needle aspiration biopsy is generally not recommended for parathyroid tumors, mainly because of the risk of tumor cells being implanted and metastasized along the needle path, and the result is susceptible to interference by thyroid cells, therefore, it is difficult to diagnose benign and malignant tumors of parathyroid gland (17).

In recent years, immunohistochemistry and DNA analysis have become increasingly important in the diagnosis of PC. Recently, the activation of tumor suppressor genes (MEN1, cdc73/HRPT2, cdkis, APC, SFRPS, GSK3 $\beta$, RASSF1A, HIC1, RIZ1, WT1, CA Sr, gna11, ap2s1) and the loss of proto oncogenes (CCND1/prad1, RET, ZFX, CTNNB1, $E Z H 2)$ in the pathogenesis of hyperparathyroidism have been found $(18,19)$. The inactivation of the CDC73/ HRPT2 Double Allele is a specific phenomenon in parathyroid malignant tumors, but the abnormal activation of Cyclin D1 and Wnt/-Catenin signal transduction is found in parathyroid benign and malignant tumors, which promotes the development of parathyroid tumors (20,21). CDC73/HRPT2is a tumor suppressor gene that encodes parafibromin protein with 531 amino acids and inhibits the occurrence of tumors by reducing the expression of CCND1 gene encoding CyclinD1 (22). The absence or decrease of the expression of parafibromin protein, or the overexpression of CyclinD1 protein is very helpful for the diagnosis of PC (23). Studies have shown that the activation mutation of GCM2 gene (24) and PRUNE2 gene mutation (25), as well as the non-expression or weak expression of RB, APC, P27 and BCL2 (6) may be related to the pathogenesis of PC. Studies conducted by Peking Union Medical College Hospital and abroad have also found that PI3K/AKT/mTOR pathway is also involved in the molecular pathogenesis of PC (6). In addition, abnormal expression of non-coding RNA including microRNA and lncRNA may also be involved in the occurrence of PC (26), lncRNA PVT1 and glis2-as1 may also become markers for diagnosing PC (27).

\section{Treatment}

Surgery is the only effective therapy. Most scholars believe that (6) surgical resection of tumor lesions is a key factor affecting the prognosis of PC. It is advisable to have an early operation after diagnosis and perform radical resection of parathyroid tumor with ipsilateral thyroid 
gland lobe including isthmus. If the tumor adheres to the surrounding soft tissue, it should be removed as widely as possible. Medical treatment is usually required before and after operation, which is generally divided into three parts: (I) Reduces and maintains blood calcium levels: Promote urinary calcium excretion. Use drugs that inhibit bone resorption, like calcitonin, bisphosphonates, RANKL inhibitors and drugs that inhibit PTH secretion, such as calcium sensitive receptor modulators. Treatment of complications, such as kidney, digestive system, bone. (II) Prevent of severe hypocalcemia and its complication. Protect bones and repair existing bone damage. (III) Drug treatment for recurrent hypercalcemia.

Peritoneal dialysis or hemodialysis may be considered to reduce serum calcium in patients with refractory or renal insufficiency. PC is generally not sensitive to chemoradiotherapy. For local lesions, such as lung metastasis and vertebrae metastasis, radiofrequency ablation has also been reported to destroy the metastasis (6).

\section{Follow-up}

Some literatures (10) reported that the 5- and 10-year survival rates were $82.3 \%$ and $66 \%$, respectively. Adverse survival prognostic factors include early surgical excision of only parathyroid gland, lymph node and distant metastasis, recurrence, refractory high serum calcium, and high serum calcium level at recurrence (6). Cervical lymph node metastasis is the most common recurrence site, such as regional lymph node, thyroid tissue and cervical anterior muscle group, and lung, bone and liver metastases followed. Most patients with recurrence die of severe complications caused by hypercalcemia, such as arrhythmia, severe dehydration, renal impairment. In order to control the serum calcium, reoperation should be considered. But even reoperation excision lesion, the recurrence rate is higher, and many patients need multiple surgical treatment.

Studies have found that PC patients with CDC73 gene mutation and/or parafibromin or CASR protein deletion are more likely to relapse or metastasize, and have a poor survival rate (6). The case 7 had relapsed three years after the first operation, and no recurrence has been found since the second operation. The other five patients had no recurrence, and one patient died of severe pneumonia. According to the consensus of Chinese experts, lifelong follow-up, regular monitoring of serum calcium and PTH are be recommended. In general, the patients were followed up once every three months for the first three years, and every six months for three to five years, and once a year thereafter. When recurrence is suspected, neck ultrasound, CT, MRI and other related examinations should be improved.

To sum up, PC is a rare endocrine malignancy that is usually diagnosed only when it invades adjacent tissues, locally recurred or metastasized. To improve the diagnosis and treatment of PC in China, it is more necessary for us to continuously summarize domestic and foreign experience, establish reliable PC molecular pathological markers, achieve new imaging positioning technology, carry out translational medical research on PC, and management of $\mathrm{PC}$ in order to improve results.

\section{Acknowledgments}

Funding: None.

\section{Footnote}

Conflicts of Interest: All authors have completed the ICMJE uniform disclosure form (available at http://dx.doi. org/10.21037/tcr-19-2368). The authors have no conflicts of interest to declare.

Ethics Statement: The authors are accountable for all aspects of the work in ensuring that questions related to the accuracy or integrity of any part of the work are appropriately investigated and resolved. The study protocol was approved by Fujian Provincial Hospital Research Ethics Committee (K2019-06-030) and informed consent was obtained from all patients. Patient consent for research use of data was obtained for each case presented. All identification data of the patients were removed from medical records prior to data collection. De-identified data were used, and it was not possible to trace any of the data to the actual individual. Only information required for coherent description of cases was extracted. Data in electronic format were accessible to authorized personnel only. No intervention other than recording, counting and analysing of data took place.

Open Access Statement: This is an Open Access article distributed in accordance with the Creative Commons Attribution-NonCommercial-NoDerivs 4.0 International License (CC BY-NC-ND 4.0), which permits the noncommercial replication and distribution of the article with the strict proviso that no changes or edits are made and the original work is properly cited (including links to both the 
formal publication through the relevant DOI and the license). See: https://creativecommons.org/licenses/by-nc-nd/4.0/.

\section{References}

1. Sadler C, Gow KW, Beierle EA, et al. Parathyroid carcinoma in more than 1000 patients: a population-level analysis. Surgery 2014;156:1622.

2. Wang PS, Xue S, Wang S, et al. Analysis of 234 cases of Parathyroid carcinoma in China. Chin J Endocr Surg 2017;11:334-7.

3. Agarwal S, Kumar T, Sharm M, et al. Parathyroid carcinoma with contralateral subcutaneous and breast recurrences: a rare presentation. Head Neck 2016;38:E115-E118.

4. Ning G. Case Reports of Endocrine and Metabolic Diseases in Rui-jin Hospital. Shanghai Scientific \&Technical Publishers, 2016;1:274-279.

5. Goswamy J, Lei M, Simo R. Parathyroid carcinoma. Curr Opin Otolaryngol Head Neck Surg 2016;24:155-62.

6. Society of Parathyroid and Metabolic Bone Disease, Rare Disease Society, Chinese Research Hospital Association. Expert consensus on the management of parathyroid carcinoma. Chin J Endocrinol Metab 2019;35:361-8.

7. Zhao L, Liu JM, He XY, et al. The changing clinical patterns of primary hyperparathyroidism in Chinese patients: data from 2000 to 2010 in a single clinical center. J Clin Endocrinol Metab 2013;98:721-8.

8. Wang O, Wang C, Nie M, et al. Novel HRPT2/CDC73 gene mutations and loss of expression of parafibromin in Chinese patients with clinically sporadic parathyroid carcinoma. PLoS One 2012;7:e45567.

9. Ferraro V, Sgaramella LI, Di Meo G, et al. Current concepts in parathyroid carcinoma: a single Centre experience. BMC Endocr Disord 2019;19:46.

10. Wang XW, Zhang L, Chen G. The diagnosis and surgery of parathyroid carcinoma Clin Surg 2018;26:410-2.

11. Libánský P, Adámek S, Broulík P, et al. Parathyroid carcinoma in patients that have undergone surgery for primary hyperparathyroidism. In Vivo 2017;31:925.

12. Stern S, Mizrachi A, Strenov Y, et al. Parathyroid adenoma: a comprehensive biochemical and histological correlative study. Clin Otolaryngol 2017;42:381-6.

13. Xue S, Chen H, Lv C, et al. Preoperative diagnosis and prognosis in 40 Parathyroid Carcinoma Patients. Clin Endocrinol (Oxf) 2016;85:29-36.

14. Cetani F, Pardi E, Marcocci C. Parathyroid Carcinoma. Front Horm Res 2019;51:63-76.

15. Schantz A, Castleman B. Parathyroid carcinoma. A study of 70 cases. Cancer 1973;31:600-5.

16. Shakeel S, Mubarak M. Proliferative lesions of parathyroid glands: an update for practicing pathologists. J Coll Physicians Surg Pak 2016;26:51-9.

17. Kim J, Horowitz G, Hong M, et al. The dangers of parathyroid biopsy. J Otolaryngol Head Neck Surg 2017;46:4.

18. Duan K, Gomez HK, Mete O. Clinicopathological correlates of hyperparathyroidism. J Clin Pathol 2015;68:771-87.

19. Kaji H. Pathophysiology of primary hyperparathyroidism. Clin Calcium 2016;26:815-20.

20. Serrano-Gonzalez M, Shay S, Austin J, et al. A germline mutation of HRPT2/CDC73 (70 G>T) in an adolescent female with parathyroid carcinoma: first case report and a review of the literature. J Pediatr Endocrinol Metab 2016;29:1005-12.

21. Starker LF, Akerstrom T, Long WD, et al. Frequent germline mutations of the MEN1, CASR, and HRPT2/CDC73 genes in young patients with clinically non-familial primary hyperparathyroidism. Horm Cancer 2012;3:44-51.

22. Lin L, Zhang JH, Panicker LM, et al. The parafibromin tumor suppressor protein inhibits cell proliferation by repression of the c-mycproto-oncogene. Proc Natl Acad Sci U S A 2008;105:17420-5.

23. Mittendorf EA, McHenry CR. parathyroid carcinoma. J Surg Oncol 2005;89:136-42.

24. El Lakis M, Nockel P, Guan B, et al. Familial isolated primary hyperparathyroidism associated with germline GCM2 mutations is more aggressive and has a lesser rate of biochemical cure. Surgery 2018;163:31-4.

25. Yu W, McPherson JR, Stevenson M, et al. Whole-exome sequencing studies of parathyroid carcinomas reveal novel PRUNE2 mutations, distinctive mutational spectra related to APOBEC-catalyzed DNA mutagenesis and mutational enrichment in kinases associated with cell migration and invasion. J Clin Endocrinol Metab 2015;100:E360-364.

26. Hu Y, Zhang X, Cui M, et al. Verification of candidate microRNA markers for parathyroid carcinoma. Endocrine 2018,60:246-54.

27. Zhang $X, \mathrm{Hu} Y$, Wang $M$, et al. Profiling analysis of long non-coding RNA and mRNA in parathyroid carcinoma. Endocr Relat Cancer 2019;26:163-76.

Cite this article as: Zheng $\mathrm{Y}$, Wen J, Lin W, Lin L, Chen G. Approach to parathyroid carcinoma (PC): seven cases and a review of the literature. Transl Cancer Res 2020;9(8):4982-4987. doi: 10.21037/tcr-19-2368 